\title{
The Application of Micro-course in the Teaching Process of Up-to-date Mechanics
}

\author{
Ziping Wang*, MeiXia Li, Riquan Lai and Naifu He \\ Faculty of Civil Engineering and Mechanics \\ Jiangsu University \\ Zhenjiang, China \\ *wzp@ujs.edu.cn
}

\begin{abstract}
The application of micro-course in education is more and more widespread. In the view of the shortage of previous teaching in the advanced course of mechanics, this paper aims to explore the application of micro-course in the teaching of advanced mechanics and explore the application of micro teaching mode in the teaching process of advanced course in mechanics. Then we will build a teaching platform based on micro-course to provide students with a way to further understand the course, which can stimulate students' interest in learning and develop their thinking skills and so as to improve the quality of teaching.
\end{abstract}

Keywords - micro-course; up-to-date mechanics; secondary teaching component

\section{INTRODUCTION}

With the improvement of teaching conditions and the deepening of the reform of teaching methods, new teaching forms including micro-course continue to emerge. Microcourse refers to the new curriculum standards and teaching practice requirements, with video as the main carrier, recording the process of teacher' $s$ teaching and learning around a knowledge point or teaching activities carried out throughout the wonderful teaching and learning activities in and out of classroom [1]. Micro-course was first proposed by David Penrose at San Juan Institute in New Mexico, USA [2]. In July 2004, Britain started the teacher television channel and generally recognized teachers, each program video duration of 15 minutes, the accumulation of resources up to 350,000 minutes of micro-video programs. In the fall of 2008, David Penrose, a one-minute professor at the San Juan Institute in New Mexico, became famous for pioneering the 'Microcourse' [3], an influential one-minute video. The core idea of it is to require teachers to combine teaching content with teaching objectives closely linked to produce a more focused learning experience. The most prominent feature of the micro-course is students can recognize the whole through observation of the part, therefore we can use micro- lecture [4-7] to drive students' enthusiasm for learning. Micro-course is different from the traditional single-type teaching materials, teaching materials, teaching design, teaching reflection and other teaching resources, and it is also a new type of teaching resource inherited and developed on the basis of traditional single-type teaching. Education authorities and universities attach great importance to the promotion of micro-course because of its

Identify applicable sponsors: Key High-education Reform Foundation of Jiangsu University (Grants No. 2017JGZD025), The Postdoctoral Online Program of Jiangsu Province (S080100D23013). useful supplement to conventional teaching activities, and make micro-course teaching play an increasingly important role in teaching. Based on the learning experiences of other courses, this paper studies the application of micro-course in "Mechanics Frontier" and has received remarkable results.

\section{MiCRO - ClAss Design In MECHANICS CUTTING - EDGE COURSE}

\section{A. Curriculum Introduction}

This course mainly focuses on mechanics, the basic theory of professional mechanics, the hot issues in the form of expert lectures. This courses are as shown in below.

(1) Theories of coupled forces and multiphysics and theories of structural damage / fracture,

(2) Theories and applications of nonlinear dynamics and control,

(3) Critical mechanics issues in engineering,

(4) Continuum media Mechanics and its applications,

(5) Micro/nano mechanics, multi-scale mechanics and testing techniques.

This course introduces a lot of practical and engineering application examples, incorporating the latest scientific research achievements. These lectures basically cover the main research directions and branches of mechanics. During the lectures, the lecturers will lead students to a comprehensive understanding of the relevant cutting-edge topics in various fields of mechanics and the application of mechanics in engineering (civil engineering, aerospace, mechanical engineering, new material design and utilization, biomedicine, environmental protection, etc.). As a result, students are guaranteed a broad understanding of mechanics. Through the learning of this course, students can recognize the important role played by mechanics and the prominent position in mechanics in social progress, as well as a vivid example introduction of the application of mechanics in daily life so that students can experience the beauty and charm of mechanics.

\section{B. Micro-course Design Process}

In traditional mechanics teaching, books are mainly used as the carrier of knowledge. However, knowledge in books is 
limited. In class, teachers spend a lot of time writing on the blackboard. Teachers need to continue to take measures to stimulate student interest in learning, to mobilize their enthusiasm. However, due to limited time for students to focus their energies, it is difficult to always concentrate on listening to lectures, so the quality of teaching cannot be guaranteed. The micro-video duration is in line with the concentration of students. In mechanics teaching, there are many key and difficult points, and there are too many formulas and large amount of exercises. In the traditional class, some students cannot fully understand the knowledge points that teachers teach. Some knowledge in mechanics before and after the coherence is strong, the front point of knowledge if not mastered, will have an impact on the later learning. Because of existing tense hours, teachers can solve some of the questions and answers, but not unlimited knowledge of a point, cannot solve the timely needs of students. The emergence of micro class provides a convenient channel for the solution of these problems. Through the repeated learning of micro class, students can deepen the mastery and understanding of knowledge points.

The core component of 'micro-course' is the classroom teaching video, as well as supplementary teaching resources such as material courseware, practice tests, student feedback and teacher's comments related to the teaching topic. They jointly create a semi-structured and thematic resource unit application "small environment" by a certain organizational relationship and presentation. Micro-course practice is as shown in Fig. 1 below.

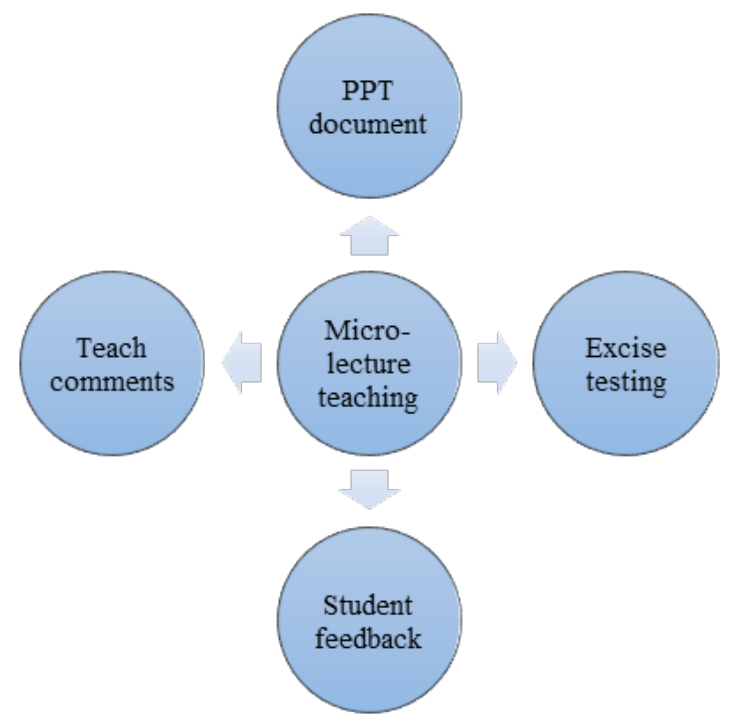

Fig. 1. Micro-course experimental process

For example, in the chapter of key mechanical problems in engineering, it is difficult for students to understand what important engineering problems are in large engineering. However, in the micro class, the teacher will collect relevant materials in advance, such as 'super engineering' video, so that students intuitively feel some of the key mechanics in the forefront of engineering problems. After watching the video, the teacher asks questions, students talk about the video review. Students are also profoundly aware of the application and importance of mechanics in engineering and improve the enthusiasm and initiative of study. In teaching process, from the teaching mode of giving priority to teaching and discussion, the teaching mode is gradually transferred to the teaching and research. With teachers and students participated in, the cultivation of students' theoretical knowledge and the improvement of practical ability are organically combined.

\section{PRACTICE ASSESSMENT OF MiCRO LEARNING RESOURCE IN THE FOREFRONT OF MECHANICAL}

\section{A. Teaching Practice}

The specialized courses taught in our school have a large amount of information and limited time for classes while students cannot digest and expand their knowledge timely in the classroom. As a result, it is difficult for them to implement knowledge goals, ability goals and emotional goals and then they usually lost interested in the specialized courses inducing lower attendance. Based on the school resources, the ability of teachers and students' interest, the relatively independent and complete small-scale curriculum organized by theme modules has the characteristics of 'short', 'small', 'refined' and 'live', suitable for various stages and types of courses. Based on the new curriculum standards and teaching practice, taking teaching-video as the foremost way of presenting, micro-course reflects the combination of various teaching resources used and generated by teachers against some knowledge point or part of the teaching activities. Micro-course has many advantages, such as highlight thematic, diverse types, the scene true, interactivity, reproducible, easy to use, and so on. From the research and practice of different levels and regions, it can be seen that in the new context of network technology and the reform of the new curriculum, the design and implementation of micro-curriculum not only have higher requirements on teachers' ability of information technology teaching and resource development, but also realized the effective supplement to the resources of teachers' teaching and the resources of students' learning. Micro-course enhances the flexibility of learning time for students, which is a useful supplement to traditional classroom teaching. And finally, it stimulates students' interest in learning so that students can recognize the prominent position of mechanics in social progress.

\section{B. Assessment Method}

The introduction of micro-teaching in cutting-edge mechanics teaching is a useful exploration of teaching practice, thus assessment is an important part in teaching method. As shown in Fig. 2, the assessment forms are divided into online assessment and offline assessment. Online assessment must use the network. The corresponding test platform will open after the end of each course, and students ought to finish all the which is only single-choice questions, within 15 minutes. Students can log in the test page only after learning the corresponding chapters. Each test has 10 questions, each question is 10 points, and the online tests score is the usual points. And the average score of all the online test is counted as $10 \%$ of the final results. Written test at the end of the period is 
the offline assessment, and test questions include indefinite choice, noun explanation, comprehensive analysis, calculation. The full score is 100 points, and students written test score account $70 \%$ of final score. In addition, teachers will leave corresponding assignments at the end of each course. Credits will be given based on the completion of assignments, and the full score is 100 points. This part will account for $20 \%$ of the final grade. Students whose final score greater than or equal to 90 will be given excellent, the score of 80 or more is good, the score of 60 or more is qualified, and the score of less than 60 is unqualified.

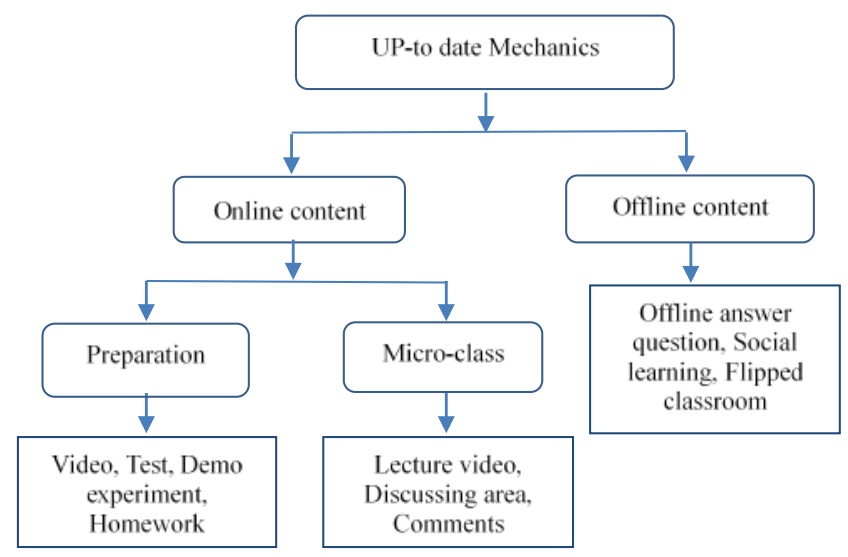

Fig. 2. Implement process

Practice has proved that micro-course in the forefront of mechanics had made the students significantly increased interest in learning. Compared with the previous student achievement, learning quality of mechanical undergraduate's 'mechanics cutting-edge' was improved significantly in 2016. Due to the application of micro-course, the passing rate is $100 \%$, the excellent rate is $70 \%$, the proportion of students with 90 or above is 38\%. Through the combination of course teaching and micro-course teaching in this course, students' understanding of the background of mechanics and the enthusiasm and initiative of learning are obviously enhanced. At the same time, the quality and efficiency of teaching are also improved, and the teaching philosophy in colleges and universities is updated.

\section{SUMMARY}

As a leading course in mechanics, Mechanics Frontier plays an important role in follow-up study of mechanics majors and helps students understand the main research directions and branches of mechanics. The purpose of the application of micro course is to better serve teachers 'teaching and students' learning. 'Mechanics Frontier' is a very suitable course for micro-course learning. Compared with the traditional video class resources closed, resource consolidation, difficult to modify, the main teacher teaching. Micro-course has its own advantages obviously, such as easy to search, easy to spread, wide range of applications, and micro-course recording objects, learning objects can be anyone, to solve the key and difficult issues of the traditional teaching with are hard to solve. Teachers' guidance, students' autonomous learning, and willingness to learn have been brought into full play, and their achievements have been remarkably improved, thus achieving the expected goal.

\section{ACKNOWLEDGMENT}

This work was financially supported by the Key Higheducation Reform Foundation of Jiangsu University (Grants No. 2017JGZD025), The Postdoctoral Online Program of Jiangsu Province (S080100D23013).

\section{REFERENCES}

[1] Z. Wang, Y. Luo and Y. Qu, "Application of Micro-course For Engineering Mechanics Experimental Teaching”, International Journal of Innovation and Research in Educational Sciences, vol. 4, pp. 23495219, April, 2017.

[2] D. Shieh. "These Lectures Are Gone in 60 Seconds", Chronicle of Higher Education, vol, 26, pp. 1-13, February, 2009.

[3] Q. Zhu, M. Zhu, Z. Chen and Z. Tang. "The C programming micro lecture designing mode study in mobile learning circumstance”, Bio Technology: An Indian Journal, vol. 10, pp. 9475-9480, May, 2014.

[4] S. Lou,N. Chen,H. Tsai,K.Tseng and R. Shih, "Using Blended Creative Teaching: Improving a Teacher Education Course on Designing Materials for Young Children”, Australasian Journal of Educational Technology, vol.28, pp. 776-792, May, 2012.

[5] X. Liao, "Comparative Analysis on Micro-lecture Teaching between China and Abroad", Journal of Vocational and Technical Education, vol. 32, pp. 88-90, September, 2014.

[6] M. Liu and Z. Zhu, "The design analyze and mode construction of micro lecture”, China Educational Technology, vol, 2, pp. 127-131, March, 2012.

[7] M. Cai, D. Li and X. Li. "Application Research of 'Micro Lecture' Based on 'Shadow Teaching'”, Intonation Journal of Information and Education Technology, Vol. 6, pp. 976-979, December, 2016. 